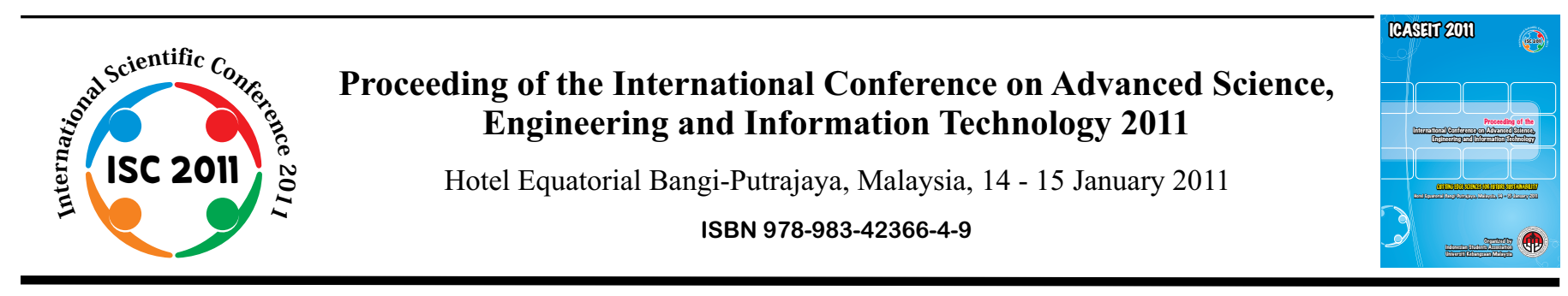

\title{
Fracture Behaviour of Tropical Hardwood Under Tensile Load
}

\author{
W.Y.H Liew, K.B.Yeo, Mohd Azlan bin Ismail \\ School of Engineering and Information Technology, University Malaysia Sabah \\ Jalan UMS, Kota Kinabalu, 88400, Malaysia \\ Tel.:+6088-320000 ext 3000,E-mail: lanz_mr@ums.edu.my
}

\begin{abstract}
This paper reports on the fracture behavior of a hard wood known as Selanga Batu (Shorea spp) with different structure under tensile stress at various strain rates $(10-100 \mathrm{~mm} / \mathrm{min})$. It was found that the structure had significant effect on the modulus of elasticity and yield strength of the wood. Wood with high percentage of ray parenchyma exhibited lower modulus of elasticity and yield strength. Ray parenchyma in wood acted as the weakest plane for crack to propagate in a step-wise manner. However, large variation found in test results make it not possible to evaluate whether the strain rate affects the ultimate strength and the fracture strain. Since the values of the modulus of elasticity obtained at a given strain rate had very small variation, the effect of strain rate on the modulus of elasticity and yield strength could be examined. It was found that the strain rate did not affect the modulus of elasticity and the yield strength of the wood.
\end{abstract}

Keyword: Failure, crack, microstructure, mechanical properties

\section{INTRODUCTION}

Dill-Langer et al. [1] reported that soft wood failed in a brittle manner when subjected to tensile stress parallel to the fiber. The relationship between the applied force and displacement was nearly linear to failure, and failure was sudden and catastrophic. The experiment results showed that the rupture and the strength of wood was governed by the flaws distributed along the fibers and the tensile strength decreased with an increase in the size of the wood specimen. In the tensile test carried out on a soft wood, Galicki and Czech [2] found that the density of the wood had significant influence on the tensile strength of wood i.e. the tensile strength increased with an increase in the density of the wood. When tensile stress was applied along the grain, the wood ruptured either transversely to the grain or along the grain. Other workers [3] had reported splinter fracture due to the high degree of anisotropy of the wood in the tension test carried out parallel to the grain. The tensile strength and elastic modulus along the grain could be in the range of 10-20 times higher than those of measured across the grain [3],[4].

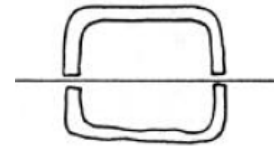

Transwall

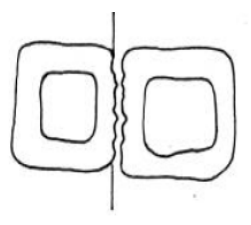

Intra wall

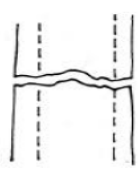

Transverse transwall

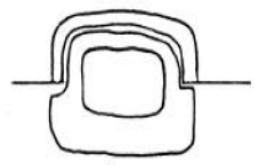

Intercellular
Fig. 1 Types of fracture of cells [8]

Several workers have carried out in situ tensile tests on various wood samples to continuously monitor the crack initiation and propagation, and fracture mechanism [5]. There are three types of fracture: transwall, intrawall, and intercellular (Fig 1). Transwall failure is a result crack propagation across the wall. Intrawall failure is due to cracking within the cell wall and around the lumen. 
Intercellular failure occurs at the middle lamella and represents the separation of wall. When comparing the fractured surfaces of green and dried specimens fractured in tension, Kifetew et al. [6] found that in the latter case, transwall failure occurred and fracture of green specimens had been dominated by intrawall failure. Transwall failures normally occurred on thin-walled cells, such as the early wood tracheids in softwoods and vessel, and parenchyma cells in hardwoods. Fracture in low density wood tends to be transwall, while for higher density wood both transwall and intercellular fracture are likely to take place [7].

\section{MATERIALS AND METHODS}

Fracture behavior of Selanga Batu (Shorea spp) under tensile stress was carried out on an Instron Universal Testing Machine at the rates of 10, 20, 50, 70 and $100 \mathrm{~mm} / \mathrm{min}$. Selangan Batu which has been widely grown in tropical countries is characterized as hard wood. The gage length of the wood specimen was $180 \mathrm{~mm}$. The length and width of the specimens were $280 \mathrm{~mm}$ and $25 \mathrm{~mm}$, respectively, as illustrated in Fig 2. The wood specimens had either $0^{\circ}$ and $45^{\circ}$ ring orientations as shown in Fig 3. All wood specimens had a similar age as they were taken from the same ring of the tree. The load versus displacement was recorded continuously during the test. From the load-displacement graph, the stressstrain graph was plotted and thus the mechanical properties of the wood were determined.

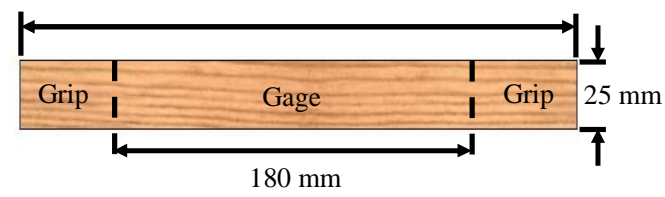

Fig. 2 Dimension of the test specimen.

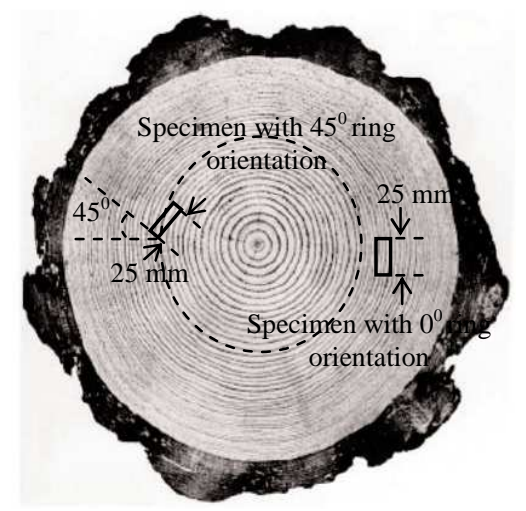

Fig 3. Wood specimens with $0^{\circ}$ and $45^{\circ}$ ring orientations were obtained from the same ring of the tree.

Density and moisture content in wood had significant influence on the modulus of elasticity, yield strength, and ultimate strength of woods[2],[9].The strength of the wood was found to decrease with an increase in the moisture content [9]. All the tests specimens used in this study had been baked to $12 \pm 1 \%$ moisture content. The density also varies between trees of the same species and between different parts of the same tree as they have different structure. The density of the wood specimens with $0^{\circ}$ and $45^{\circ}$ ring orientations after being baked was found to be $0.8976 \pm 0.013$ and $0.8972 \pm 0.010$, respectively.

\section{FAILURE MODE}

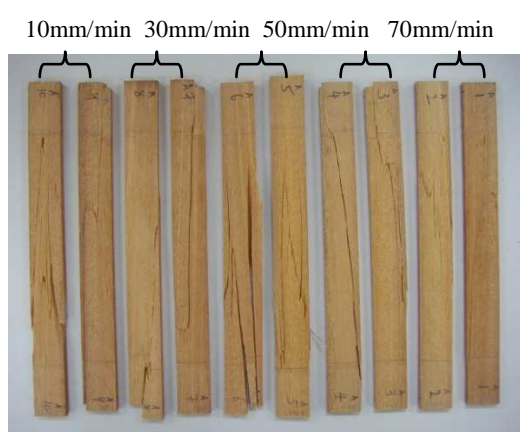

(a)

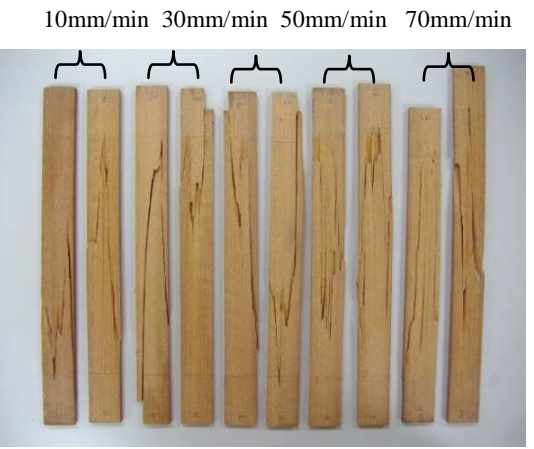

(b)

Fig. 4 Specimens with ring orientation of (a) $0^{0}$ and (b) $45^{\circ}$ after tensile test.

The specimens with different ring orientations tested at various strain rates are shown in Fig 4. Generally, there are two modes of failure: shear and splinter as shown in Fig 5. The specimens failed in shear mode has been due to crack propagating in a direction about $45^{\circ}$ to the applied stress. The crack propagation of in splinter mode is complex. The initial crack may start anywhere in the gage transversely as primary crack before propagating in zigzag direction as shown in Fig 5(b). Initial crack is difficult to locate and identify after an audible initial "burst" sound of the breaking of fiber. It has been found that specimens with the ring orientation of $0^{0}$ failed in shear mode. Whereas, specimens with the ring orientation of $45^{\circ}$ failed in splinter mode. No change in the failure mode with strain rate has been observed.

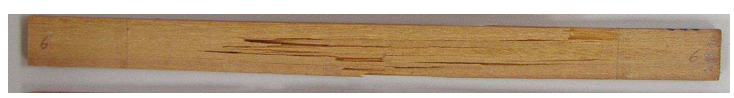

(a)

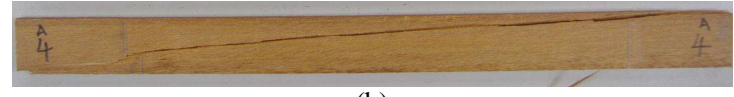

(b)

Fig. 5 (a) Shear and (b) splinter failure are the two common failure patterns observed on the tested specimens. 


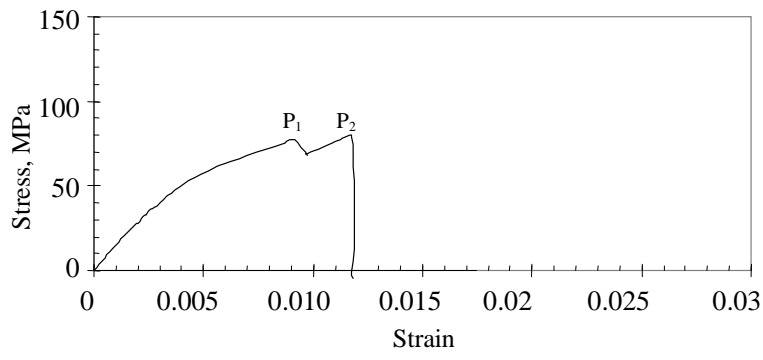

Fig. 6 Stress-strain curve obtained in the test conducted at $10 \mathrm{~mm} / \mathrm{min}$ using wood with ring orientation of $45^{\circ}$.

If the test specimen fractured completely after the crack had propagated, a rapid drop in the load would be observed and a burst sound would be heard. In some circumstances, two "burst" sounds were heard. The stress caused the first "burst" sound is $P_{1}$ as indicated in Fig 6. Upon reaching $P_{1}$, a sudden drop followed by an increase in the stress was observed. After reaching the second peak value of $P_{2}$, the stress dropped to 0 as the specimen had completely lost its load-bearing capacity. In many tests, the value of $P_{2}$ was found to be higher than the $P_{1}$. This indicates that the specimen still had high load-bearing capacity after the first rupture. On the conservative side, the first peak value i.e. $P_{1}$ was taken as the ultimate strength of the wood.

\section{MECHANICAL PROPERTIES FROM STRESS-STRAIN GRAPH}

The modulus of elasticity and yield strength for the woods with different ring orientations determined from the tensile tests are shown in Table 1 . The modulus of the wood is the initial linear slope part of the stress-strain graph. The yield strength is the stress value of the intersection point between the straight line parallel to the slope of the stress-strain graph at $0.2 \%$ strain and the stress-strain curve.

The wood specimens with the same ring orientation tested at a given speed fractured at the strain of between 0.10 and 0.35 . Tests carried out on the wood specimens with the same ring orientation at a given speed gave ultimate strength values of between $70-145 \mathrm{~N} / \mathrm{mm}^{2}$. Fig 7 shows that the tests, conducted at the same strain rate using specimens with the same fiber orientation, give very different values of ultimate strength and fracture strain. Due to a significant variation in the test results, it is not possible to evaluate whether the strain rate affects the ultimate strength and the fracture strain. Since the values of the modulus of elasticity obtained at a given strain rate has very small variation of $2 \%$, the effect of strain rate and fiber orientation on the modulus of elasticity can be examined. However, it has been found that the strain rate did not affect the modulus of elasticity and the yield strength of the wood. The wood with $90^{\circ}$ ring orientation has higher modulus of elasticity and yield strength than the wood with $45^{0}$ ring orientation. This indicates that the wood with $45^{\circ}$ fiber orientation has weaker structure.
TABLE I

MECHANICAL PROPERTIES OF THE WOOD WITH (a) $0^{\circ}$ AND (b) $45^{\circ}$ RING ORIENTATION OBTAINED FROM THE TENSILE TESTS USING DIFFERENT STRAIN RATE. WOOD WITH $90^{\circ}$ RING ORIENTATION HAD HIGHER MODULUS OF ELASTICITY AND YIELD STRENGTH THAN THE WOOD WITH $45^{\circ}$ RING ORIENTATION. STRAIN RATE DID NOT AFFECT THE MODULUS OF ELASTICITY AND THE YIELD STRENGTH.

\begin{tabular}{|c|c|c|}
\hline $\begin{array}{c}\text { Strain rate } \\
(\mathbf{m m} / \mathbf{m i n})\end{array}$ & $\begin{array}{c}\text { Modulus of elasticity } \\
\left(\mathbf{N} / \mathbf{m m}^{\mathbf{2}}\right)\end{array}$ & $\begin{array}{c}\text { Yield strength } \\
(\mathbf{M P a})\end{array}$ \\
\hline 10 & 14392 & 69.00 \\
\hline 30 & 14946 & 71.00 \\
\hline 50 & 15485 & 72.00 \\
\hline 70 & 14800 & 69.50 \\
\hline 100 & 14893 & 70.00 \\
\hline
\end{tabular}

(a)

\begin{tabular}{|c|c|c|}
\hline $\begin{array}{c}\text { Strain rate } \\
(\mathbf{m m} / \mathbf{m i n})\end{array}$ & $\begin{array}{c}\text { Modulus of elasticity } \\
\left(\mathbf{N} / \mathbf{m m}^{\mathbf{2}}\right)\end{array}$ & $\begin{array}{c}\text { Yield strength } \\
(\mathbf{M P a})\end{array}$ \\
\hline 10 & 16505 & 82.50 \\
\hline 30 & 16245 & 81.25 \\
\hline 50 & 16422 & 78.00 \\
\hline 70 & 16562 & 79.50 \\
\hline 100 & 16410 & 82.00 \\
\hline
\end{tabular}

(b)
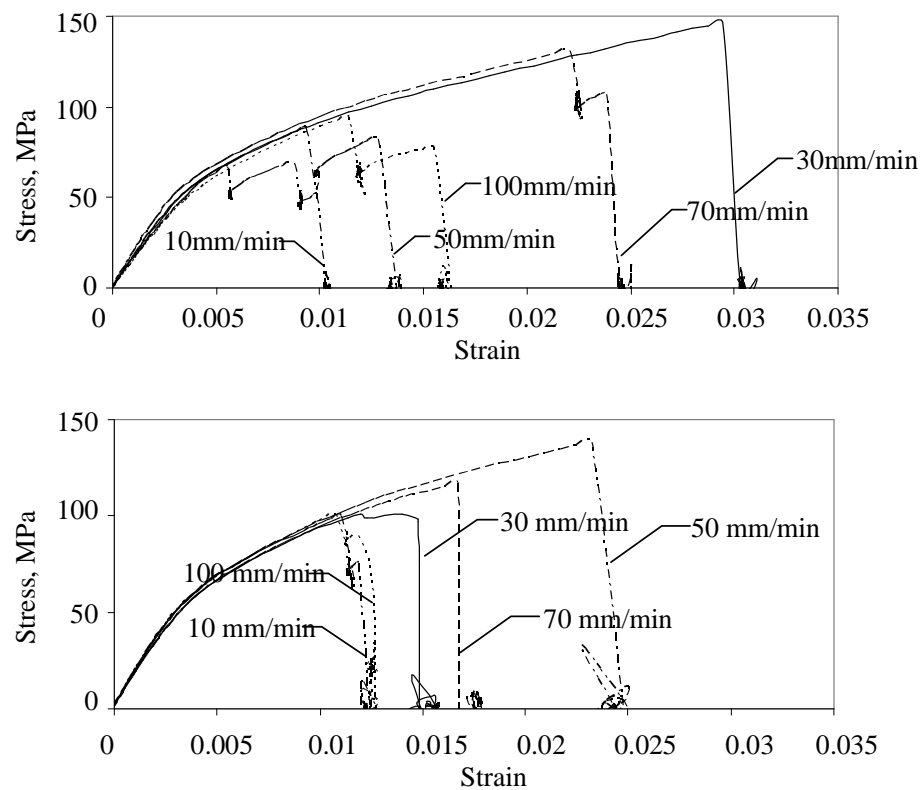

Fig. 7 Stress-strain curves obtained for woods with ring orientation of $0^{0}$ at various strain rates. For a given strain rate, the ultimate strength and fracture strength varied between $100-145 \mathrm{MPa}$ and $0.01-0.035$, respectively.

\section{MiCROSCOPIC INVESTIGATION}

Scanning electron microscope (SEM) is used to investigate the failure in the microstructure cells including the type of failures. Specimens with $0^{0}$ and $45^{\circ}$ ring orientations showed evidence of intercellular (IC), intrawall (IW) and transwall (TW) failures. Specimens with $0^{0}$ and $45^{\circ}$ had different structure which resulted in different crack propagation mechanisms. Specimens with $45^{\circ}$ ring orientation has more ray parenchyma (refer to Fig 8) that serves as failure points. The cell wall of the rays is thin compared to the fiber. It is likely that crack is initiated at the ray parenchyma as it is the main spot of mechanical weakness in bulk wood subjected to tension perpendicular to the grain [10]. 


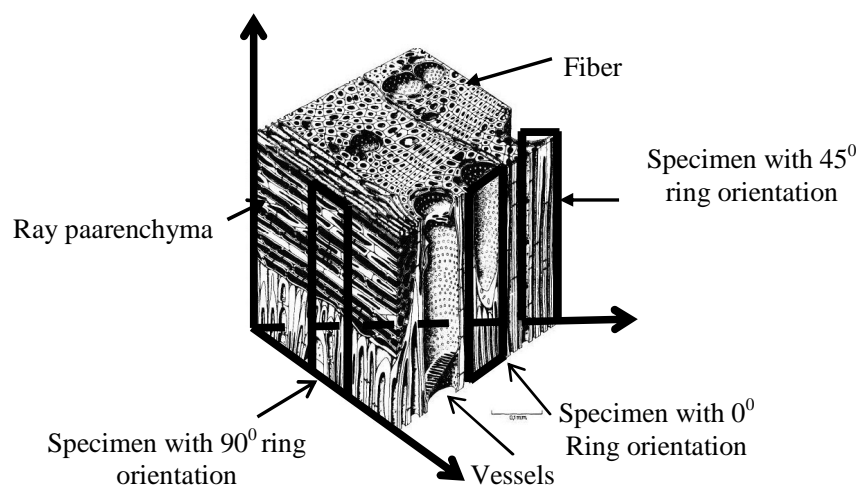

Fig. 8 Microstructure of wood specimens with different orientations [8].

Failure mechanism for specimen with $45^{\circ}$ ring orientation can be explained as the schematic in Fig 9. When tensile load is applied to the rectangular cross section specimen, radial ray parenchyma is subjected to high stress concentration, which will eventually lead to the initial crack at the bonding between rays and fibre and rays to rays. Two crack propagation mechanisms are possible i.e. crack propagation in $A$ manner due to weak bonding between rays and crack propagation in $B$ manner due to the thin cell wall of the rays parenchyma. The fracture mechanism can proceed in a step-wise manner from the first plane of normal ray $A$ to the second plane of ray $B$ [11]. This explains why cracks formed in wood with 450 ring orientation propagate in a zigzag manner, resulting in step-like fractured surface as shown in Fig 10.

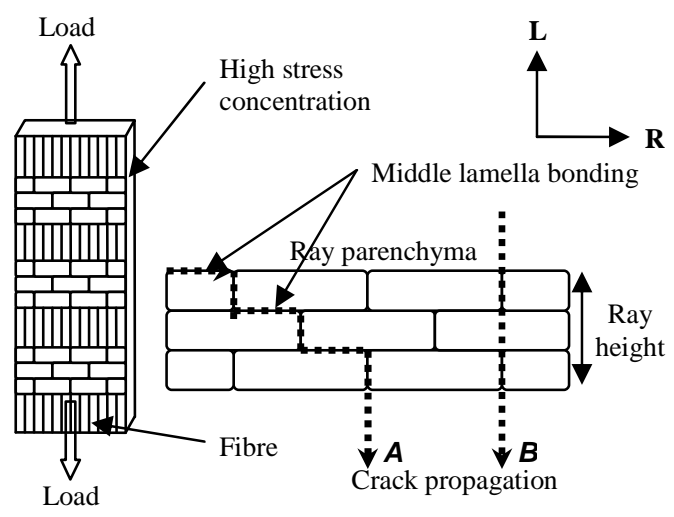

Fig. 9 Crack propagation in wood with $45^{\circ}$ ring orientation.

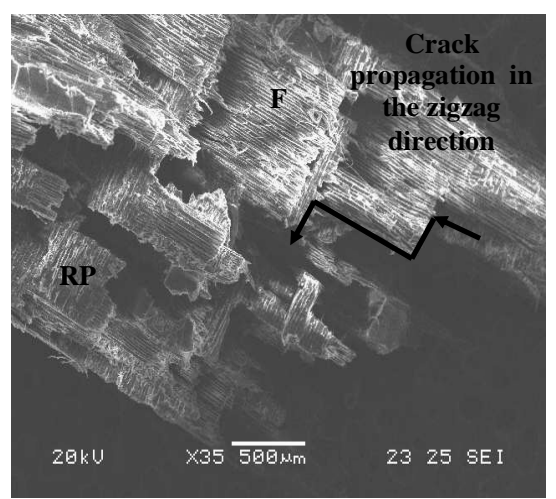

Fig. 10 Fracture surface produced by crack propagation in the zigzag direction. F: fibre, RP: rays parenchyma.

\section{CONCLUSION}

Fracture behavior of a hard wood known as Selanga Batu (Shorea $\mathrm{spp}$ ) with different structure under tensile stress at various strain rates $(10-100 \mathrm{~mm} / \mathrm{min})$ was investigated. It was found that the structure had significant effect on the modulus of elasticity, the yield strength of the wood and the crack propagation. Wood with high percentage of ray parenchyma exhibited lower modulus of elasticity and yield strength. It was also found that the strain rate did not affect the modulus of elasticity and the yield strength of the wood. Due to large variation in the ultimate strength and fracture strain, it has not been possible to evaluate whether the strain rate affects the ultimate strength and the fracture strain.

\section{ACKNOWLEDGMENT}

We would like to thank Causal Productions for permits to use and revise the template provided by Causal Productions. Original version of this template was provided by courtesy of Causal Productions (www.causalproductions.com).

\section{REFERENCES}

[1] Dill-Langer, G., R.C. Hidalgo, F. Kun, Y. Mareno, S. Aicher and H.J. Herrmann, 2003. Size dependency of tension strength in natural fiber composites, Physica A, 325: 547-560.

[2] Galicki, J. and M. Czech, 2005. Tensile strength of softwood in LR orthotropy plane, Mechanics of materials, 37: 677-686.

[3] Schniewind, A.P. and R.A. Pzniak, 1971. On the fracture toughness of Douglas Fir wood, Engineering Fracture Mechanics, 2: 223-233.

[4] Kollman, F.F.P. and Jr. W.A. Cote, 1968. Principles of Wood Science and Technology, Solid Wood, Springer-Verlag, New York, 1: 294-296.

[5] Sippola, M. and K. Frühmann, 2002. In situ Longitudinal Tensile Tests of Pine Wood in an Environmental Scanning Electron Microscope, Holzforschung, 56: 669-675.

[6] Kifetew, G.F., L. Thuvander, Berglund and H. Lindberg, 1998. The effect of drying on wood fracture surfaces from specimens loaded in wet condition. Wood Science and Technology, 32: 83-94.

[7] Smith, I, E. Landis and M. Gong, 2003. Fracture and fatigue in wood, John Wiley and Sons, LTD, England.

[8] River, B.H., C.B. Vick and R.H. Gillespie, 1991. Wood as an adherend, Treatise on adhesion and adhesives, Marcel Dekker, Inc, New York.

[9] Reiterer A. and S. Tschegg, 2002. The influence of moisture content on mode I fracture behavior of sprucewood, Journal of Materials Science, 37: 4487-4491.

[10] Bodner, J.G. Grüll and M. Schlag, 1997. Fracture initiation and progress in wood specimens stressed in tension. Holzforschung, 51: 487-490.

[11] Côté, W.A. and R.B. Hanna, 1983. Ultrastructural characteristics of wood fracture surfaces, Wood and Fiber Science, 15:135-163. 